International Journal of Environmental Research and

Public Health

ISSN 1660-4601

www.mdpi.com/journal/ijerph

Article

\title{
Different Choices of Drinking Water Source and Different Health Risks in a Rural Population Living Near a Lead/Zinc Mine in Chenzhou City, Southern China
}

\author{
Xiao Huang ${ }^{1,2}$, Liping He ${ }^{2, *}$, Jun $\mathrm{Li}^{2}$, Fei Yang ${ }^{3}$ and Hongzhuan Tan ${ }^{1, *}$ \\ 1 Department of Epidemiology and Health Statistics, School of Public Health, Central South \\ University, Changsha, Hunan 410008, China; E-Mail: huangxiao1998@163.com \\ 2 Department of Hygiene, School of Public Health, Xiangnan University, Chenzhou, Hunan 423000, \\ China; E-Mail: lijun5006@126.com \\ 3 Department of Occupational Health and Environmental Health, School of Public Health, Central \\ South University, Changsha, Hunan 410008, China; E-Mail: phfyang@csu.edu.cn \\ * Authors to whom correspondence should be addressed; E-Mails: hlipingm@163.com (L.H.); \\ tanhz@csu.edu.cn (H.T.); Tel.: +86-735-2653-155 (L.H.); +86-731-8885-8435 (H.T.).
}

Academic Editor: Paul B.Tchounwou

Received: 14 July 2015 / Accepted: 5 November 2015 / Published: 12 November 2015

\begin{abstract}
This study aimed to describe the households' choices of drinking water sources, and evaluate the risk of human exposure to heavy metals via different drinking water sources in Chenzhou City of Hunan Province, Southern China. A cross-sectional face-to-face survey of 192 householders in MaTian and ZhuDui village was conducted. The concentrations of heavy metals in their drinking water sources were analyzed. Carcinogenic and non-carcinogenic risk assessment was performed according to the method recommended by the United States Environmental Protection Agency. In total, $52.60 \%$ of the households used hand-pressed well water, and 34.89\% used barreled water for drinking. In total, $6.67 \%$ of the water samples exceeded the Chinese drinking water standards. The total health risk of five metals is $5.20 \times 10^{-9} \sim 3.62 \times 10^{-5}$. The total health risk of five metals was at acceptable levels for drinking water sources. However, the total risk of using hand-pressed well water's highest value is 6961 times higher than the risk of using tap water. Household income level was significantly associated with drinking water choices. Arsenic (As) and lead $(\mathrm{Pb})$ are priority controlled pollutants in this region. Using safe drinking water (tap water, barreled water and so on) can remarkably reduce the risk of ingesting heavy metals.
\end{abstract}


Keywords: drinking water; heavy metals; risk assessment; environmental epidemiology; mining activities

\section{Introduction}

Safe drinking water is universally recognized as critical components of public health. Heavy metal contamination, such as from lead $(\mathrm{Pb})$, cadmium $(\mathrm{Cd})$, mercury $(\mathrm{Hg})$ and metalloid arsenic (As), in drinking water has been receiving increasing attention in China recently [1-3]. Health risk assessment is crucial to understanding the potential health risks from heavy metal exposure in humans. This information is very important for decision-makers when setting up policies or regulations to protect the population's health. More and more drinking water studies have applied health risk assessments in their studies [4-10]. The levels of heavy metals are frequently detectable in various types of drinking water, and these levels can be used to estimate potential health risk. However, these monitoring studies for water contaminants are often accompanied by surveys relying solely on the concentration of heavy metal in drinking water; thus, they fail to account for specific water sources (hand-pressed well water, bottled water, and tap water) and water use habits. Exposure assessment for water contaminants has typically relied upon drinking water consumption patterns rather than water chemical analysis [11].

China is one of the largest producers and consumers of lead and zinc in the world. Chenzhou City has huge reserves of mineral resources and raw material resources and is rich in varieties. It is called the "Nonferrous Metal Village" and it is the most important area of the multi-mineral belt in Hunan Province. In 1985, the collapse of the tailing dam in the Chenzhou lead/zinc mine led to the spread of mining waste spills on farmland along the Dong River. In that disaster, a strip of farmland about $400 \mathrm{~m}$ wide on both sides of the Dong River channel was covered with a layer of black sludge that was about $15 \mathrm{~cm}$ thick. After the collapse of the dam, an emergency soil cleanup procedure was quickly carried out in some places. The toxic sludge and a major portion of the contaminated surface soil were mechanically removed. Nevertheless, numerous reports indicate that water, soil, vegetables and dust have been heavily polluted by $\mathrm{Pb}, \mathrm{As}, \mathrm{Zn}$ and $\mathrm{Cd}$ near the mining areas [12-16].

Exposure to heavy metals via drinking water remains a present health threat to many populations, particularly in areas of developing countries that have insufficient water treatment facilities [17-19]. In recent years, numerous health-related pollution incidents associated with heavy metals have been widely reported in China [20,21], especially the high lead levels in the blood of children in Chenzhou [22,23]. These incidents have raised great concern. Previous research showed that the risk perception of drinking water is an important factor on the use of alternative water sources [24]. It is therefore anticipated that the choices of drinking water source in this area might be affected from those reports. However, no survey has yet been conducted in any Chinese region where lead/zinc and lead mineral resources are widely distributed [25], and a large population is potentially exposed to relatively high contaminant levels. 
With the significant social and economic achievements that have taken place in the past three decades, lifestyle and health beliefs have drastically changed in recent years in China. Bottled water, barreled water, and household filtrated water have successively entered into family life [26]. More than a single source of potable water is used in each family. Studies have suggested that the choice of a household drinking water source is influenced by many factors [24,27,28], such as socioeconomic status, health risk perceptions, water suppliers, the perception of water quality, trust in water suppliers, familiarity, cultural differences, etc. However, water surveys have traditionally been used in epidemiologic, marketing, or economic studies; few studies have incorporated water source and use habit surveys into health risk assessments for heavy metal contamination in drinking water in a rural populations living near a lead/zinc mine.

This study aimed to (1) describe the change in rural residents' drinking water consumption under the background of the environment; (2) evaluate and compare the risk of human exposure to heavy metals via different drinking water sources; and (3) explore influential factors on household drinking water consumption.

\section{Material and Methods}

\subsection{Study Area}

The study area included MaTian and ZhuDui villages, selected according to previous research [12], in the Suxian District of Chenzhou City, Hunan Province, Southern China. Chenzhou City lies between $24^{\circ} 53^{\prime}$ and $26^{\circ} 50^{\prime} \mathrm{N}$ latitude and between $112^{\circ} 13^{\prime}$ and $114^{\circ} 14^{\prime} \mathrm{E}$ longitude (Figure 1). The total area of the city is $19,400 \mathrm{~km}^{2}$, out of which 241,560 ha are paddy areas and 59,420 ha are vegetable areas. The climate is subtropical, and the average rainfall is about $1500 \mathrm{~mm}$. In the city, about 10,000 people are engaged in mining [13]. The research area is located about $10 \mathrm{~km}$ east of the Shi Zhu Yuan mine, which is one of the biggest industrial districts in Chenzhou, and is home to the mining and smelting of $\mathrm{Pb}, \mathrm{Zn}, \mathrm{W}$, and Mo. In this area, mining activities for heavy metals have been conducted for 500 years. More than 3800 workers are engaged in the mining, smelting, and transport services associated with the mining activities, which continue at full speed today. On 25 August 1985, the big tailing pool dam of the Shi Zhu Yuan mine collapsed because of heavy rainfall [12]. After the accident, some emergency soil cleanup measures were quickly carried out in some places, and a major portion of the contaminated surface soil was mechanically removed. Nevertheless, most of the contaminated farmlands are still presently cultivated. There were some previous studies on heavy metal pollution in soils and plants around this area [12-14].

Drinking water in the valley mainly stems from privately dug wells and, to a smaller extent, from the communal water supply of Chenzhou City. 


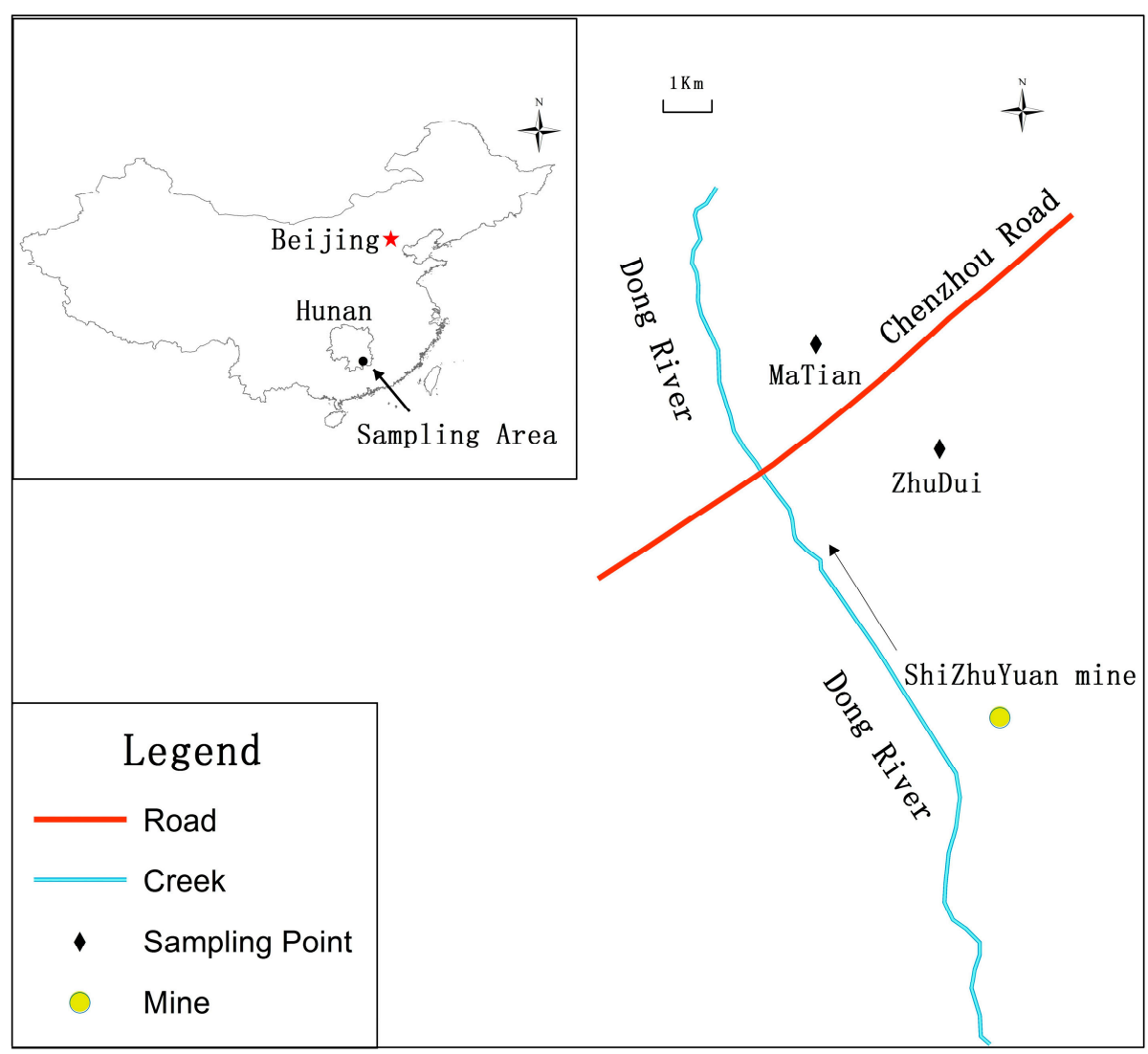

Figure 1. Map of the locations of the two sampling villages in Chenzhou $\mathrm{Pb} / \mathrm{Zn}$ mine area in Hunan province (southern China).

\subsection{Questionnaire Survey}

This was a cross sectional study conducted in Chenzhou, Southern China during August 2013. Firstly, a sampling frame of all households containing at least one qualified subject, aged 18 years or above, living in the study area for more than 1 year, and giving informed consent, was prepared. Those individuals with mental or physical challenges making it too difficult to participate in the study were excluded from the study. A household list was obtained from the township hospitals. Secondly, the two villages are divided into 12 groups according to location and administrative district division; 16 households were selected by simple random technique from each group. One hundred and ninety two households were selected using stratified random sampling method. Efforts were made to interview the head of the household. If the household was locked or no eligible participant was found at the time of interview, the household was either revisited on the subsequent day or an additional household was chosen. All interviews were conducted during the daytime in participants' homes.

A face-to-face survey of 192 householders in MaTian and ZhuDui village was conducted. The questionnaire was designed to include both socio-demographic characteristic variables and their water consumption. The main research contents are given as follows: (1) contact information, sampling, global positioning system (GPS), re-contact information; (2) socio-demographic characteristics; and (3) water source types, well depths, whether the well adequately sealed, and water treatment facilities. The study was approved by the ethical committee of Xiangnan University. Written informed consent was obtained from every respondent prior to participation. Questionnaires were performed by rigorously 
trained third-year students of Xiangnan University. The questionnaire was pre-tested with a convenient sample of individuals. Questions that were unclear or otherwise problematic were revised. Subsequently, we performed a pilot study using twenty residents who were randomly selected from our sampling frame. Based on the results, minor revisions were made to decrease the length of the questionnaire. In order to maximize our response rate, health clinicians in the township hospitals and village clinics and the local Center for Disease Control and Prevention went from door to door to mobilize residents to take part in the investigation. A small gift valued at $\$ 4$ was given to participants to thank them for participation. The response rate for participating in the questionnaire was $100 \%$.

\subsection{Water Sampling and Determination the Concentrations of Heavy Metals}

The water quality survey points were randomly selected proportional to the number of users. According to the research reported by Chinese Center for Disease Control and Prevention [29], 74.87\% of rural population use underground water (hand-pressed wells water), and $25.13 \%$ use surface water (open wells water and spring water). Moreover, there is only one spring water sample point in the two villages. Therefore, about 12 hand-pressed wells water samples, 2 open wells water samples and 1 spring water sample were selected, respectively. Tap water and barreled water were safe water because their qualities meet the Chinese drinking water standards (GB5749-2006); the concentrations of all the heavy metals were very low. Thus, only one tap water and one barreled water was sampled, respectively. A total of 17 water samples were collected from the two villages.

Water samples were collected on 15 August 2013. Samples were acidified in situ with concentrated nitric acid $\left(\mathrm{HNO}_{3}\right)$ to $\mathrm{pH}<2$ and stored in a refrigerator at $4{ }^{\circ} \mathrm{C}$ for further pretreatment. Water sample collection and preservation and the five heavy metals were measured according to standard methods [30]. The concentrations of $\mathrm{As}$ and $\mathrm{Hg}$ in the water samples were measured with an atomic fluorescence spectrophotometer (AFS-830, Beijing Titan Instruments $\mathrm{Co}$, China), and $\mathrm{Pb}, \mathrm{Cd}$, and $\mathrm{Zn}$ concentrations were determined by an atomic absorption spectrophotometer (AAS, ZEEnit 700, Analytik Jena, Germany). The detection limits were $0.01,0.008,0.008,0.008$ and $8 \mu \mathrm{g} \cdot \mathrm{L}^{-1}$ for $\mathrm{Pb}, \mathrm{Cd}, \mathrm{As}, \mathrm{Hg}$, and $\mathrm{Zn}$, respectively. The coefficient of variation of intra-assay and inter-assay was less than $5 \%$. The recoveries for the six elements were in the range of $94 \%$ to $105 \%$.

\subsection{Health Risk Assessment}

Risk assessment normally includes data collection and analysis, exposure assessment, toxicity assessment, and risk characterization.

(a) Exposure Assessment: The exposure dosage through ingestion pathway was calculated by Equation (1) [30]:

$$
A D D=\frac{C_{S} \times I R \times E F \times E D}{B W \times A T}
$$

where the average daily dose (ADD) is the average daily dose of each metal through ingestion pathway $\left(\mathrm{mg} \cdot \mathrm{kg}^{-1} \cdot \mathrm{day}^{-1}\right)$, Cs the concentration of heavy metal in water $\left(\mathrm{mg} \cdot \mathrm{L}^{-1}\right)$, IR is the daily intake of water $\left(\mathrm{L} \cdot \mathrm{day}^{-1}\right), \mathrm{EF}$ is the exposure frequency (days $\left.\cdot \mathrm{year}^{-1}\right), \mathrm{ED}$ is the exposure duration(years), $\mathrm{BW}$ is the 
bodyweight $(\mathrm{kg})$, and AT is the average time in days (for non-carcinogens, AT $=\mathrm{ED} \times 365$ days; for carcinogens, $\mathrm{AT}=70$ (human life expectancy) $\times 365$ days).

Due to sampling in the wet season and to avoid the risk heavy metal exposure, the highest concentration of heavy metal in water was used in the calculation. BW $(53.6 \mathrm{~kg})$ and IR $(1.85 \mathrm{~L})$ used were site-specifically measured and derived from our questionnaire survey.

(b) Risk Assessment: According to the categories of the International Agency for Research on Cancer (IARC), heavy metals are grouped by their potential carcinogenic risks. The carcinogenic and non-carcinogenic risks are usually assessed according to the guidelines in the Risk Assessment Guidance for Superfund of the US Environmental Protection Agency (EPA).

(c) Non-Carcinogenic Risk Assessment: Potential non-carcinogenic risks, as indicated by the hazard quotient (HQ), were evaluated by comparing the exposure dose of chemical contaminants according to each exposure route (water ingestion and dermal absorption) with the corresponding reference dose (RfD) using Equation (2).

$$
H Q=\frac{A D D}{R f D}
$$

where RfD is the reference dose of heavy metals in a given condition $\left(\mu \mathrm{g} \cdot \mathrm{kg}^{-1} \cdot \mathrm{day}^{-1}\right)$. The oral reference doses $\left(\mathrm{mg} \cdot \mathrm{kg}^{-1} \cdot \mathrm{day}^{-1}\right)$ were obtained from the US EPA's Integrated Risk Information System.

(d) Carcinogenic Risk Assessment: The carcinogenic risk of chemical contaminants is usually expressed by a carcinogenic risk factor, CR. When $\mathrm{CDI} \times \mathrm{SF}<0.01$, Equation (3) is applicable; otherwise, Equation (4) is used instead.

$$
\begin{gathered}
\operatorname{Risk}_{i}=A D D \times S F \\
\operatorname{Risk}_{i}=1-\exp (-A D D \times S F)
\end{gathered}
$$

where SF is the carcinogenic slope factor $\left(\mu \mathrm{g} \cdot \mathrm{kg}^{-1} \cdot \mathrm{day}^{-1}\right)$. The calculated value of $\mathrm{CR}$ is the cancer-developing probability of any type of carcinogenic chemicals over a life time exposure for a general population. The slope factor and reference dose were obtained from previous study [7,9,31,32]. According to the USEPA's guidance for acceptable or tolerable carcinogenic risks, the range of the CR value is from $10^{-6}$ to $10^{-4}$. In general, if $\mathrm{CR}<10^{-6}$, cancer risks are considered to be negligible; however, if $\mathrm{CR}>10^{-4}$, cancer risks are considered as unacceptable by most international regulatory agencies.

\subsection{Statistical Analysis}

Descriptive and inferential statistics were undertaken to analyze the data. A Chi-square test was performed to evaluate the association between socio-demographic characteristics and using barreled water for cooking. When the expected frequency was less than 5, Fisher's exact test was used instead. Heavy metal concentrations in different water sources, in different depth and different village had been compared by analysis of variance.

The relation between socio-demographic characteristics and safer drinking water consumption was assessed using binary logistic regression. Tap water and barreled water were generally considered safer because this water was high-quality treated meeting the drinking water standards set up by the Health Department of the Chinese Government. Thus, safe drinking water was defined as barreled water or tap 
water or using both barreled water and tap water for drinking in the study. A backward stepwise logistic regression model was used. A level of two-sided $p<0.05$ was considered to be statistically significant. All analysis was performed using SPSS version 13.0.

\section{Results}

\subsection{Socio-Demographic Characteristics of the Household}

A total of 192 households were enrolled in the study conducted in July 2013, in MaTian and ZhuDui village in Chenzhou City, Hunan Province, Southern China. A majority of the heads of household were males $(85.4 \%, n=164)$. In total, $95.8 \%(n=184)$ of the families were living at their current residence. A majority of the families lived in nuclear families with a family size of 3 to 7 . Approximately $3 \%$ $(n=64)$ of families had family members who had gone out as migrant workers, and $60.9 \%$ of participants self-reported that their household income was at the local average. In total, 52.6\% of participants reported that their household income was mainly used for food. The percentages of household fuel source supply depended upon were $42.2 \%$ on calor gas, $42.7 \%$ on coal, $25.5 \%$ on wood, and $16.7 \%$ on electricity. The vast majority of families $(97.9 \%, n=188)$ attended the new rural cooperative medical system. Details can be seen in Table 1.

Table 1. Socio-demographic characteristics of the study household.

\begin{tabular}{|c|c|c|}
\hline Characteristic & $(N=192)$ & No. $(\%)$ \\
\hline \multicolumn{3}{|c|}{ Head of household's gender } \\
\hline Male & 164 & 85.4 \\
\hline Female & 28 & 14.6 \\
\hline \multicolumn{3}{|l|}{ Lived at current residence } \\
\hline Always living in & 184 & 95.8 \\
\hline Moved into this place & 8 & 4.2 \\
\hline \multicolumn{3}{|l|}{ Family size } \\
\hline $1-2$ & 22 & 11.5 \\
\hline $3-4$ & 87 & 45.3 \\
\hline $5-6$ & 65 & 33.9 \\
\hline$\geq 7$ & 18 & 9.4 \\
\hline \multicolumn{3}{|c|}{ Family members go out as migrant workers } \\
\hline Yes & 64 & 33.3 \\
\hline No & 128 & 66.7 \\
\hline \multicolumn{3}{|c|}{ Self-reported household income } \\
\hline Better & 29 & 15.1 \\
\hline Average level & 117 & 60.9 \\
\hline Poor & 27 & 14.1 \\
\hline Poorer & 19 & 9.9 \\
\hline \multicolumn{3}{|c|}{ Household income is mainly used for food } \\
\hline Yes & 101 & 52.6 \\
\hline No & 91 & 47.4 \\
\hline
\end{tabular}


Table 1. Cont.

\begin{tabular}{ccc}
\hline Characteristic & $(\boldsymbol{N = 1 9 2})$ & No. $(\mathbf{\%})$ \\
\hline Food supply & & \\
\hline Household production & 48 & 25.0 \\
Half household production half purchasing & 75 & 39.1 \\
Purchasing food at local markets & 69 & 35.9 \\
\hline Fuel type & & \\
\hline Calor gas & 81 & 42.2 \\
Coal & 82 & 42.7 \\
& & \\
Wood & 49 & 25.5 \\
Electricity & 32 & 16.7 \\
Yes & & 97.9 \\
No & 188 & 2.1 \\
\hline
\end{tabular}

\subsection{Household Drinking Water and Cooking Water Consumption}

Results showed that more than half of the households $(52.6 \%, n=101)$ used hand-pressed well water for drinking; 34.9\% $(n=67)$ used barreled water; $17.7 \%(n=34)$ used tap water; $15.6 \%(n=30)$ used open wells; and 12.5\% $(n=24)$ used rivers, streams, ponds, and other surface water. The constituent ratio of household drinking water consumption was found to be as follows: $5.2 \%(n=10)$ using only barreled water; $15.6 \%(n=30)$ using only tap water; $1.0 \%(n=2)$ using both barreled water and tap water; $24.5 \%(n=47)$ using only hand-pressed well water; $26.0 \%(n=50)$ using both hand-pressed wells and barreled water; $13.5 \%(n=26)$ using only open wells; $10.4 \%(n=20)$ using only rivers, streams, ponds and other surface water; and 3.7\% $(n=7)$ using other combinations (see Figure 2). In $4.2 \%(n=8)$ of the households, barreled water was used for cooking. The majority of water consumption of barreled water resulted from the good economic conditions of the households. All cooking use barreled water was reported to be used in the households that self-reported their household income to be at the local average or better. Even so, $11.9 \%(n=8)$ of the households using barreled water had "poor" or "poorer" household incomes. Details can be seen in Table 2.

Table 2. Household water consumption in the different self-reported household income.

\begin{tabular}{cccccc}
\hline \multirow{2}{*}{$\begin{array}{c}\text { Self-Reported } \\
\text { Household Income }\end{array}$} & $\begin{array}{c}\text { Barreled Water } \\
\text { and Others }\end{array}$ & $\begin{array}{c}\text { Only Barreled } \\
\text { Water }\end{array}$ & $\begin{array}{c}\text { Only Barreled Water } \\
\text { and Hand-Pressed } \\
\text { Wells water }\end{array}$ & $\begin{array}{c}\text { Only Barreled Water } \\
\text { and Tap Water }\end{array}$ & $\begin{array}{c}\text { Cooking Use } \\
\text { Barreled Water }\end{array}$ \\
\hline Better & $18(26.9 \%)$ & $5(50.0 \%)$ & $11(22.0 \%)$ & $0(0.0 \%)$ & $3(37.5 \%)$ \\
Average level & $41(61.2 \%)$ & $5(50.0 \%)$ & $31(62.0 \%)$ & $2(100.0 \%)$ & $5(62.5 \%)$ \\
Poor or Poorer & $8(11.9 \%)$ & $0(0.0 \%)$ & $8(16.0 \%)$ & $0(0.0 \%)$ & $0(0.0 \%)$ \\
Total & $67(100.0 \%)$ & $10(100.0 \%)$ & $50(100.0 \%)$ & $2(100.0 \%)$ & $8(100.0 \%)$ \\
\hline
\end{tabular}




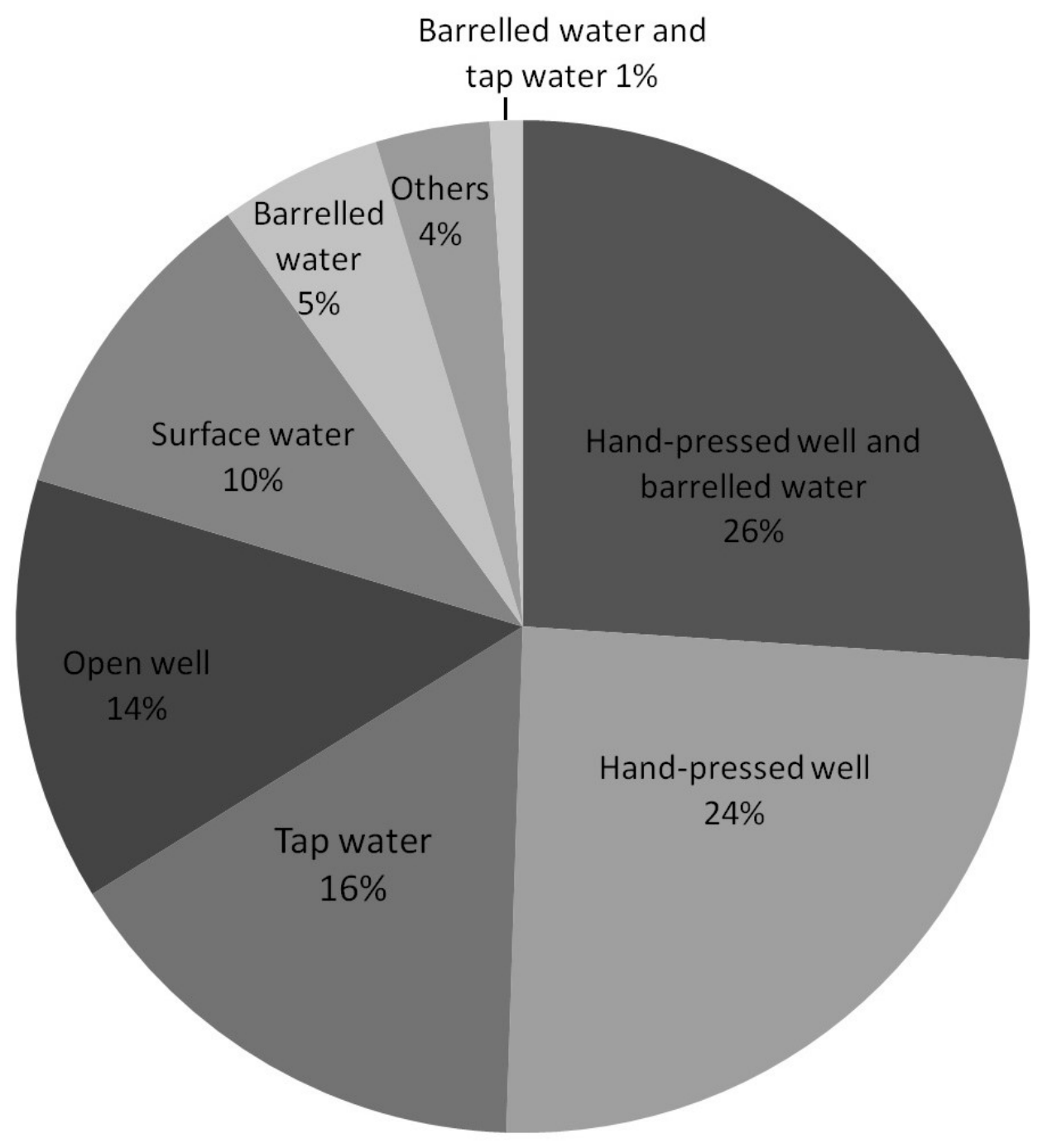

Figure 2. A pie graph of household drinking water consumption.

\subsection{Heavy Metals in Drinking Water Sources}

With the exception of $\mathrm{Pb}$, which was higher than the national standard in a hand-pressed wells water sample, the concentrations of heavy metals in drinking water from the two studied communities were well below the Chinese drinking water standards (GB 5749-2006) [29]. The concentration of Arsenic (As) in MaTian is significantly higher than in ZhuDui $(t=9.05, p<0.05)$. The concentration of the five heavy metals in different water sources in different depth was not statistically significantly different. Details can be seen in Table 3. 
Table 3. The concentrations of heavy metals in drinking water in different villages and different water source.

\begin{tabular}{|c|c|c|c|c|c|c|}
\hline \multirow{2}{*}{ Category } & \multirow{2}{*}{$n$} & \multicolumn{5}{|c|}{ Concentration (Mean (Range)) } \\
\hline & & $\mathrm{Pb}\left(\mathbf{u g} \cdot \mathbf{L}^{-1}\right)$ & $\mathrm{Cd}\left(\mathrm{ug} \cdot \mathrm{L}^{-1}\right)$ & $\operatorname{Zn}\left(\mathbf{m g} \cdot \mathbf{L}^{-1}\right)$ & $\operatorname{As}\left(\mathbf{u g} \cdot \mathbf{L}^{-1}\right)$ & $\mathbf{H g}\left(\mathbf{u g} \cdot \mathbf{L}^{-1}\right)$ \\
\hline \multicolumn{7}{|l|}{ Water source } \\
\hline Open wells & 2 & $0.06(\mathrm{BDL}-0.18)$ & $0.029(\mathrm{BDL}-0.054)$ & $0.115(0.018-0.306)$ & $0.568(0.034-1.247)$ & $0.081(0.048-0.13)$ \\
\hline \multicolumn{7}{|l|}{ Hand-pressed wells } \\
\hline Depth $<3 \mathrm{~m}$ & 4 & $3.51(\mathrm{BDL}-10.53 *)$ & $0.227(\mathrm{BDL}-0.53)$ & $0.026(0.004-0.056)$ & $3.209(0.262-4.683)$ & $0.070(0.060-0.076)$ \\
\hline Depth $=3 \sim 6 \mathrm{~m}$ & 4 & BDL & $0.02(\mathrm{BDL}-0.076)$ & $0.027(0.022-0.039)$ & $1.824(\mathrm{BDL}-5.802)$ & $0.074(0.030-0.106)$ \\
\hline Depth $>6 \mathrm{~m}$ & 4 & $\mathrm{BDL}$ & $0.126(\mathrm{BDL}-0.35)$ & $0.0195(0.006-0.033)$ & $2.582(0.059-6.428)$ & $0.047(\mathrm{BDL}-0.106)$ \\
\hline Spring water & 1 & BDL & BDL & 0.027 & 0.000 & 0.051 \\
\hline Tap water & 1 & BDL & BDL & 0.025 & BDL & BDL \\
\hline Barreled water & 1 & $\mathrm{BDL}$ & $\mathrm{BDL}$ & 0.030 & BDL & BDL \\
\hline \multicolumn{7}{|l|}{ Villages } \\
\hline MaTian & 9 & $0.824(\mathrm{BDL} \sim 10.53 *)$ & $0.098(\mathrm{BDL}-0.53)$ & $0.045(0.004-0.306)$ & $2.227(0.034-6.428) * *$ & $0.069(\mathrm{BDL}-0.13)$ \\
\hline ZhuDui & 6 & $\mathrm{BDL}$ & $0.0860(\mathrm{BDL}-0.18)$ & $0.026(0.02-0.03)$ & $0.316(\mathrm{BDL}-0.947)$ & 0.0520 \\
\hline $\begin{array}{l}\text { Chinese drinking water standard } \\
\text { (GB5749-2006) }\end{array}$ & & $10\left(\mathrm{ug} \cdot \mathrm{L}^{-1}\right)$ & $5\left(\mathrm{ug} \cdot \mathrm{L}^{-1}\right)$ & $1\left(\mathrm{mg} \cdot \mathrm{L}^{-1}\right)$ & $50\left(\mathrm{ug} \cdot \mathrm{L}^{-1}\right)$ & $1\left(\mathrm{ug} \cdot \mathrm{L}^{-1}\right)$ \\
\hline
\end{tabular}

BDL represents below detection limit, The detection limits were 0.01, 0.008, 0.008, 0.008 and $8 \mu \mathrm{g} \cdot \mathrm{L}^{-1}$ for $\mathrm{Pb}, \mathrm{Cd}, \mathrm{As}, \mathrm{Hg}$, and $\mathrm{Zn}$, respectively. * Exceeded the Chinese drinking water standards. ** The concentration of Arsenic (As) in MaTian is significantly higher than in ZhuDui. The concentrations of the five heavy metals in different water sources in differents depth were not statistically significantly different. 


\subsection{The Health Risk Assessment of Heavy Metals in Drinking Water Sources}

It is notable that the values provided below are lifetime health risks (with 70 years as the average life span). The risk of human exposure to heavy metals via drinking water are presented in (Table 4). The results showed that the total health risk is $5.20 \times 10^{-9} \sim 3.62 \times 10^{-5}$, the carcinogenic risk is $5.20 \times 10^{-9} \sim 3.62 \times 10^{-5}$, and the non-carcinogenic risk is $1.37 \times 10^{-12} \sim 4.51 \times 10^{-9}$. Carcinogens risk accounted for $99.9 \%$ of the total risk. The total health risk were lower than the maximum allowance levels recommended by International Commission on Radiological Protection (ICRP) $\left(5.0 \times 10^{-5}\right)$. The high values of cancer risks associated with exposure to carcinogenic metals via drinking water consumption were estimated to be $3.46 \times 10^{-5}$ for As and $1.59 \times 10^{-6}$ for $\mathrm{Cd}$, while the values of non-cancer risks induced by non-carcinogenic metals were estimated to be $3.71 \times 10^{-9}, 0.38 \times 10^{-9}$, and $0.13 \times 10^{-12}$ for $\mathrm{Pb}, \mathrm{Hg}$, and $\mathrm{Zn}$, respectively. The health risks caused by carcinogenic heavy metals in water were decreased in the following order: As $>\mathrm{Cd}$. The risks by the non-carcinogenic heavy metals decreased in the following order: $\mathrm{Pb}>\mathrm{Hg}>\mathrm{Zn}$.

Table 4. The health risk evaluation of heavy metals via drinking water consumption in two studied villages.

\begin{tabular}{|c|c|c|c|c|c|c|}
\hline \multirow{2}{*}{ Type } & \multicolumn{2}{|c|}{ Carcinogenic Risk } & \multicolumn{3}{|c|}{ Non-Carcinogenic Risk } & \multirow{2}{*}{$\begin{array}{c}\text { The Total } \\
\text { Health Risk }\end{array}$} \\
\hline & Cd & As & $\mathbf{P b}$ & $\mathrm{Hg}$ & $\mathbf{Z n}$ & \\
\hline Tap water & $1.50 \times 10^{-9}$ & $3.70 \times 10^{-9}$ & $0.88 \times 10^{-12}$ & $0.49 \times 10^{-12}$ & $0.41 \times 10^{-13}$ & $5.20 \times 10^{-9}$ \\
\hline Barreled water & $1.50 \times 10^{-9}$ & $3.70 \times 10^{-9}$ & $0.88 \times 10^{-12}$ & $0.49 \times 10^{-12}$ & $0.49 \times 10^{-13}$ & $5.20 \times 10^{-9}$ \\
\hline Open wells & $0.16 \times 10^{-6}$ & $0.92 \times 10^{-5}$ & $0.06 \times 10^{-9}$ & $0.32 \times 10^{-9}$ & $0.11 \times 10^{-12}$ & $0.94 \times 10^{-5}$ \\
\hline Hand-pressed wells & $1.59 \times 10^{-6}$ & $3.46 \times 10^{-5}$ & $3.71 \times 10^{-9}$ & $0.38 \times 10^{-9}$ & $0.13 \times 10^{-12}$ & $3.62 \times 10^{-5}$ \\
\hline Spring water & $1.50 \times 10^{-9}$ & $3.70 \times 10^{-9}$ & $0.88 \times 10^{-12}$ & $0.25 \times 10^{-9}$ & $0.84 \times 10^{-13}$ & $5.20 \times 10^{-9}$ \\
\hline
\end{tabular}

\subsection{Risk Comparison in Different Drinking Water Sources}

With the concentrations of heavy metals in tap water set to 1 , we calculated the corresponding ratio of other drinking water in highest value. The total risk of the groups using hand-pressed well, and open well water was significantly higher than the risks for those using tap water, barreled water, and spring water. The total risk for those using hand-pressed well water was 6961 times higher than the risk for those using tap water. It is notable that the values provided below are lifetime health risks (with 70 years as the estimated life span). The total risk of using open well water was 1807 times higher than that using tap water. The total risk of using spring water and using barreled water was the same as tap water. The non-cancer risk of using spring water was 512 times higher than the non-cancer risk of using tap water.

\subsection{The Influential Factors of Safer Drinking Water Sources}

Tap water and barreled water were generally considered safer because this water was high-quality treated meeting the drinking water standards set up by the Health Department of the Chinese Government. So safe drinking water was defined as barreled water or tap water or using both barreled water and tap water for drinking in the study. Table 5 summarizes the associations between safe drinking water consumption and the socio-demographic characteristics of the households. Household drinking water consumption was influenced by family size, household income level, the amount of household 
income used for food, and food supply sources; conversely, the gender of the head of household, the years at the current residence, the number of family members gone out as migrant workers, and the attendance to the new rural cooperative medical system showed no correlation to drinking water choices. According to a Chi-square test, no variables were significantly associated with the use of barreled for cooking. Those who reported "better household income", "purchasing food at local markets" and "household income is mainly used for food" were more likely to use safe drinking water; however, those with a family size of seven or more were less likely to use safe drinking water.

Table 5. Logistic regression models analysis of socio-demographic characteristics in household safer water consumption.

\begin{tabular}{|c|c|c|c|c|c|}
\hline Characteristics & & $\boldsymbol{\beta}$ & S.E & $\mathbf{P}$ & OR $(95 \% C I)$ \\
\hline \multirow[t]{4}{*}{ Family size } & 3-4 (Reference) & & & & \\
\hline & $1-2$ & -1.899 & 0.642 & $0.003 * *$ & $0.150(0.043,0.527)$ \\
\hline & $5-6$ & -0.255 & 0.360 & 0.479 & $0.775(0.382,1.571)$ \\
\hline & $\geq 7$ & -0.671 & 0.623 & 0.282 & $0.511(0.151,1.734)$ \\
\hline \multirow[t]{3}{*}{ Self-reported income level } & Average level (Reference) & & & & \\
\hline & Poor or poorer & 0.298 & 0.446 & 0.503 & $1.348(0.562,3.231)$ \\
\hline & Better & 1.551 & 0.528 & $0.003 * *$ & $4.714(1.674,13.279)$ \\
\hline \multirow[t]{2}{*}{$\begin{array}{l}\text { Household income mainly } \\
\text { using for food }\end{array}$} & No (Reference) & & & & \\
\hline & Yes & 0.711 & 0.363 & $0.050 * *$ & $2.036(1.000,4.144)$ \\
\hline \multirow[t]{3}{*}{ Food supply } & $\begin{array}{c}\text { Household production } \\
\text { (Reference) }\end{array}$ & & & & \\
\hline & $\begin{array}{c}\text { Half household production } \\
\text { half purchasing }\end{array}$ & 0.298 & 0.446 & 0.503 & $1.348(0.562,3.231)$ \\
\hline & Purchasing food at local markets & 1.551 & 0.528 & $0.003 * *$ & $4.714(1.674,13.279)$ \\
\hline \multirow[t]{2}{*}{$\begin{array}{c}\text { Participation in new rural } \\
\text { cooperative medical } \\
\text { treatment }\end{array}$} & No (Reference) & & & & \\
\hline & Yes & -2.492 & 1.276 & 0.051 & $0.083(0.007,1.009)$ \\
\hline
\end{tabular}

Safe drinking water choice was defined as using only barreled water, using only tap water, using only both barreled water and tap water for drinking. $* *$ Significant at $p<0.05$.

\section{Discussion}

\subsection{Household Drinking Water and Cooking Water Consumption}

Our results show that domestic drinking water choices noticeably changed. A prior survey reported that, in China, the main source of rural drinking water in water was mainly underground water, with $74.87 \%$ of the studied rural population using underground water sources, and $25.13 \%$ using surface water. In total, $55.10 \%$ of the rural population used water from centralized water supply systems. The use of domestic barreled water increased and the use of hand-pressed well water decreased, compared to the water uses of other rural residents [33]. In our study, 52.60\% used hand-pressed well water for drinking, $24.48 \%$ of households used only hand-pressed well water, and $26.04 \%$ used both 
hand-pressed well and barreled water. In total, 5.21\% of households used only barreled water for drinking, and $4.17 \%$ of the households even used barreled water for cooking. This suggests that tap water was not the main source of drinking water, hand-pressed well water was predominantly used, but barreled water was popularly used by local people for drinking and cooking. The reason might be related to people's risk perceptions of heavy metals. When people feel there are risk to their health as a result of a variety of media sources, adaptive behavior (changing the choice of drinking water sources) will be occur to avoid risk $[27,34,35]$.

\subsection{Water Quality Assessment and Health Risk Assessment of Heavy Metals}

In order to investigate the drinking water quality and evaluate the risk of human exposure to heavy metals via drinking water sources, fifteen samples collected from the household were analyzed and concentrations of five heavy metals were measured in drinking water. We found that, besides $\mathrm{Pb}$, in a hand-pressed well water sample, the other heavy metal contents were lower than the national standards. In total, $6.67 \%$ exceeded the Chinese drinking water standards. The findings supported previous similar findings. Previous studies showed that in their study areas, the water quality in poor, good, and excellent status during the dry season accounted for $5 \%, 10 \%$, and $85 \%$ of the total rural ground water sources, respectively, while during the wet season, it accounted for 5\%,5\%, and 90\%, respectively. This was determined using a single-factor assessment method and Nemerow index methods at twenty sampling points [36]. The measurements from fifteen well water samples indicated that the collapse of the tailing dam and mining activity in the area does not distinctly impair the natural quality of most of the well water.

Based on the concentration of heavy metals in drinking water sources, the carcinogenic and non-carcinogenic risk assessments were performed according to the methods recommended by the United States EPA. Our study found that the total health risk of five metals was lower than the maximum allowance levels recommended by ICRP $\left(5.0 \times 10^{-5}\right)$. The results indicate that the health risk for the five heavy metals in the region were at acceptable levels for drinking water sources. Perhaps, the local people's perception of the risk of heavy metal exposure via drinking water was actually overestimated. Too much worry about the risks of drinking water is unnecessary.

The $\mathrm{Pb}$ was in excess of the standards, but its health risk was lower than those of arsenic and cadmium. Carcinogenic risks accounted for $99.9 \%$ of the total risk. This indicated that the health risk caused by the carcinogenic heavy metals was much larger than those caused by the non-carcinogenic heavy metals, and As was the greatest potential risk. Corresponding pollution control strategies may need to be implemented for public health protection purposes. In the non-carcinogenic pollutants, $\mathrm{Pb}$ is the priority controlled pollutant in this region.

In order to evaluate the effectiveness of people's behaviors, we compared the health risk in different drinking water sources. With the concentrations of heavy metals in tap water set at 1 , we found that the total risk of using hand-pressed well and open well water group was significantly higher than tap water, barreled water, and spring water. The total risk of using hand-pressed well water was 6961 times higher than that of using tap water. The total risk of using open well water was 1807 times higher than that of using tap water. The total risk of using spring water and using barreled water was the same as that of tap water. The non-cancer risks of using spring water were 512 times higher than that of using tap water. It is notable that values provided below are lifetime health risks (70 years as the life span). The survey 
shows that different choices of drinking water source led to different health risks. Using safe drinking water can remarkably reduce the risk of the ingestion of heavy metals through water. These results coincide with those of previous studies $[4,37,38]$.

\subsection{The Influential Factors of the Choice of Drinking Water Sources}

In order to provide references for later work in the field of environmental health education and behavior intervention, the relation between safer water choices and socio-demographic characteristics was firstly assessed by univariable logistic regression. Our findings show that safer household water choices were correlated with household income level, family size, the household income being mainly used for food, and food supply source. These findings are in line with previous studies $[26,39,40]$. A strong correlation was found between household income level and domestic drinking water choices ( $p=0.003$ ) using a backward stepwise logistic regression model. Out of the three household income level groups, the better household income group was about five times (odds ratio 4.71) more likely to use tap water and barreled water than the average level group. However, the poor and poorer income level groups were less significant $(p>0.05)$ than the average level group. Family size, household income mainly being used for food, and the choice of food supply source were also found to be closely related to household income level. The greater the family size was, the more spending was found to be used for drinking water. Perhaps, in order to save money, some families tended to choose hand-pressed well water because it does not require additional money.

There are several limitations to the current study. This study only measured five kinds of heavy metals in drinking water to evaluate the risk of harm to human body health. Our approach only considered the intake levels during the wet season, without considering the other poisonous and harmful substances that can produce health risks; therefore, the evaluation actually underestimated the risk of heavy metal exposure. Daily water consumption, exposure frequency, exposure duration, and people's risk perceptions of heavy metals were not included in this investigation. Selection bias and underrepresentation may have occurred because only two village residents were recruited and 17 water samples were selected for detection. Thus, in this paper, the drinking water health risk assessment of heavy metals in the region is preliminary.

\section{Conclusions}

We found that hand-pressed well water was mainstream, while the use of drinking water sources noticeably changed with an increase in barreled water. With the exception of $\mathrm{Pb}$, the concentrations of heavy metals in drinking water were well below the Chinese drinking water standards. The total health risk caused by the five metals was lower than the maximum allowance levels recommended by the ICRP and was at acceptable levels for drinking water sources. As and $\mathrm{Pb}$ are priority controlled pollutants in this region. The total risk of using hand-pressed well water in highest value was 6961 times higher than that of using tap water. Using safe drinking water (tap water and barreled water) can greatly reduce the risks of ingesting heavy metals through drinking water. Households making safer water choices were correlated with household income level, family size, the household income mainly being used for food, and food supply source. A strong correlation was also found between household income level and household drinking water choices. 


\section{Acknowledgments}

This work was supported by the construct program of The Key Discipline in Hunan Province (2011-76), A Project Supported by Scientific Research Fund of Hunan Provincial Education Department (2015B224) and the National Science Foundation of China (81502787). The authors wish to thank all of the residents for their participation in this study. The authors acknowledge Rui-xue Huang, Junxia Yan and all those who contributed their time and talent to the creation and review of this article.

\section{Author Contributions}

Xiao Huang and Liping He conceived and designed the whole study. Jun Li, Fei Yang, Yanbin Meng and Yangyun Ou were involved with the study design, respondents recruitment, data collection and sample analysis. Jun Li, Hongzhuan Tan, were involved with the modification of the questionnaire. Xiao Huang performed statistical analysis and drafted the manuscript. Fei Yang and Hongzhuan Tan revised the manuscript. All authors read and approved the final version.

\section{Conflicts of Interest}

The authors declare that there is no conflict of interest.

\section{References}

1. Zhang, J.; Mauzerall, D.L.; Zhu, T.; Liang, S.; Ezzati, M.; Remais, J.V. Environmental health in China: Progress towards clean air and safe water. Lancet 2010, 375, 1110-1119.

2. Tao, T.; Xin, K. Public health: A sustainable plan for China's drinking water. Nature 2014, 511, 527-528.

3. Rodriguez-Lado, L.; Sun, G.; Berg, M.; Zhang, Q.; Xue, H.; Zheng, Q.; Johnson, C.A. Groundwater arsenic contamination throughout China. Science 2013, 341, 866-868.

4. Zhang, L.; Mo, Z.; Qin, J.; Li, Q.; Wei, Y.; Ma, S.; Xiong, Y.; Liang, G.; Qing, L.; Chen, Z.; et al. Change of water sources reduces health risks from heavy metals via ingestion of water, soil, and rice in a riverine area, South China. Sci. Total Environ. 2015, 530-531, 163-170.

5. AbRazak, N.H.; Praveena, S.M.; Aris, A.Z.; Hashim, Z. Drinking water studies: A review on heavy metal, application of biomarker and health risk assessment (a special focus in Malaysia). J. Epidemiol. Glob. Health 2015, 5, doi:10.1016/j.jegh.2015.04.003.

6. Zhaoyong, Z.; Abuduwaili, J.; Fengqing, J. Heavy metal contamination, sources, and pollution assessment of surface water in the Tianshan Mountains of China. Environ. Monit. Assess. 2015, 187, doi:10.1007/s10661-014-4191-X.

7. Yang, X.; Duan, J.; Wang, L.; Li, W.; Guan, J.; Beecham, S.; Mulcahy, D. Heavy metal pollution and health risk assessment in the Wei River in China. Environ. monit. Assess. 2015, 187, doi:10.1007/s10661-014-4202-y.

8. Yao, H.; Qian, X.; Gao, H.; Wang, Y.; Xia, B. Seasonal and spatial variations of heavy metals in two typical Chinese rivers: concentrations, environmental risks, and possible sources. Int. J. Environ. Res. Public Health 2014, 11, 11860-11878. 
9. Lu, S.Y.; Zhang, H.M.; Sojinu, S.O.; Liu, G.H.; Zhang, J.Q.; Ni, H.G. Trace elements contamination and human health risk assessment in drinking water from Shenzhen, China. Environ. monit. Assess. 2015, 187, doi:10.1007/s10661-014-4220-9.

10. Kavcar, P.; Sofuoglu, A.; Sofuoglu, S.C. A health risk assessment for exposure to trace metals via drinking water ingestion pathway. Int. J. Hyg. Environ. Health 2009, 212, 216-227.

11. Andra, S.S.; Makris, K.C. Incorporating potable water sources and use habits into surveys that improve surrogate exposure estimates for water contaminants: The case of bisphenol A. J. Water Health 2014, 12, 81-93.

12. Liu, H.; Probst, A.; Liao, B. Metal contamination of soils and crops affected by the Chenzhou lead/zinc mine spill (Hunan, China). Sci. Total Environ. 2005, 339, 153-166.

13. Liao, X.Y.; Chen, T.B.; Xie, H.; Liu, Y.R. Soil As contamination and its risk assessment in areas near the industrial districts of Chenzhou City, Southern China. Environ. Int. 2005, 31, 791-798.

14. Lei, M.; Zhang, Y.; Khan, S.; Qin, P.F.; Liao, B.H. Pollution, fractionation, and mobility of Pb, Cd, $\mathrm{Cu}$, and $\mathrm{Zn}$ in garden and paddy soils from a $\mathrm{Pb} / \mathrm{Zn}$ mining area. Environ. Monit. Assess. 2010, 168, 215-222.

15. Leung, H.M.; Ye, Z.H.; Wong, M.H. Survival strategies of plants associated with arbuscular mycorrhizal fungi on toxic mine tailings. Chemosphere 2007, 66, 905-915.

16. Song, D.; Zhuang, D.; Jiang, D.; Fu, J.; Wang, Q. Integrated Health Risk Assessment of Heavy Metals in Suxian County, South China. Int. J. Environ. Res. Public Health 2015, 12, 7100-7117.

17. Zheng, Y.; Ayotte, J.D. At the crossroads: Hazard assessment and reduction of health risks from arsenic in private well waters of the northeastern United States and Atlantic Canada. Sci. Total Environ. 2015, 505, 1237-1247.

18. Brouwer, R.; Job, F.C.; van der Kroon, B.; Johnston, R. Comparing willingness to pay for improved drinking-water quality using stated preference methods in rural and urban Kenya. Appl. Health Econ. Health Policy 2015, 13, 81-94.

19. Fox, D.I.; Pichler, T.; Yeh, D.H.; Alcantar, N.A. Removing heavy metals in water: The interaction of cactus mucilage and arsenate (As (V)). Environ. Sci. Technol. 2012, 46, 4553-4559.

20. Larson, C. Environmental science. China gets serious about its pollutant-laden soil. Science 2014, 343, 1415-1416.

21. Yang, H.; Huang, X.; Thompson, J.R.; Flower, R.J. China's soil pollution: Urban brownfields. Science 2014, 344, 691-692.

22. Yin, H. "Lead poisoning cases"-Focus Tracking. Labour Prot. 2011, 34-36.

23. Zhou, Y.; He, L.; Huang, X.; He, J. Lead exposure of people living in a lead high exposure area from local diet. J. Hyg. Res. 2011, 40, 741-743.

24. DoriaMde, F.; Pidgeon, N.; Hunter, P.R. Perceptions of drinking water quality and risk and its effect on behaviour: A cross-national study. Sci. Total Environ.2009, 407, 5455-5464.

25. Zhang, X.; Yang, L.; Li, Y.; Li, H.; Wang, W.; Ye, B. Impacts of lead/zinc mining and smelting on the environment and human health in China. Environ. Monit. Assess. 2012, 184, 2261-2273.

26. Hanyi, C. Yaying, Z. Change of water consumption and its potential influential factors in Shanghai: A cross-sectional study. BMC Public Health 2012, 12, 450-459. 
27. Dupont, D.; Waldner, C.; Bharadwaj, L.; Plummer, R.; Carter, B.; Cave, K.; Zagozewski, R. Drinking water management: Health risk perceptions and choices in First Nations and non-First Nations communities in Canada. Int. J. Environ. Res. Public Health 2014, 11, 5889-5903.

28. Chappells, H.; Campbell, N.; Drage, J.; Fernandez, C.V.; Parker, L.; Dummer, T.J. Understanding the translation of scientific knowledge about arsenic risk exposure among private well water users in Nova Scotia. Sci. Total Environ. 2015, 505, 1259-1273.

29. Zhang, R, Li, H.X.; Wu, X.F,; Fang, H.C.; Sun, B.Y.; Wang, Z.S.; Zhang, Q.; Tao, Y. Current situation analysis on china rural drinking water quality. J. Environ. Health 2009, 26, 3-5.

30. Standard Examination Methods for Drinking Water-Microbiological Parameters. Available online: http://www.lancarver.com/UpFiles/pdf/2014-01-19/011915111072.pdf (accessed on 14 July 2015).

31. Risk Assessment Guidance for Superfund: Volume III-Part A, Process for Conducting Probabilistic Risk Assessment. Available online: http://nepis.epa.gov/Exe/ZyNET.exe/ P10088O5.TXT?ZyActionD $=Z$ yDocument $\&$ Client $=$ EPA\& $\&$ Index $=2000+T h r u+2005 \& D o c s=\& Q u$ ery $=\&$ Time $=\&$ EndTime $=\&$ SearchMethod $=1 \&$ TocRestrict $=$ n $\&$ Toc $=\&$ TocEntry $=\& Q$ Field $=\& Q F i e$ ldYear $=\& Q$ FieldMonth $=\& Q$ FieldDay $=\&$ IntQFieldOp $=0 \&$ ExtQFieldOp $=0 \& X m l Q u e r y=\&$ File $=D$ $\% 3 \mathrm{~A} \backslash$ zyfiles $\backslash$ Index\%20Data $\backslash 00$ thru05 $\backslash$ Txt $\backslash 00000024 \backslash \mathrm{P} 1008805$.txt\&User=ANONYMOUS\&Pass word $=$ anonymous \&SortMethod $=\mathrm{h} \mid-\&$ MaximumDocuments $=1 \&$ FuzzyDegree $=0$ \&ImageQuality $=\mathrm{r}$ 75g8/r75g8/x150y150g16/i425\&Display $=$ p|f\&DefSeekPage $=x \& S e a r c h B a c k=Z y$ ActionL\&Back $=$ ZyActionS\&BackDesc $=$ Results\%20page $\&$ MaximumPages $=1 \&$ ZyEntry $=1 \&$ SeekPage $=x \& Z y P U$ RL (accessed on 14 July 2015).

32. Wongsasuluk, P.; Chotpantarat, S.; Siriwong, W.; Robson, M. Heavy metal contamination and human health risk assessment in drinking water from shallow groundwater wells in an agricultural area in Ubon Ratchathani province, Thailand. Environ. Geochem. Health 2014, 36, 169-182.

33. Ribera, G.; Clarens, F.; Martinez-Llado, X.; Jubany, I.; Marti, V.; Rovira, M. Life cycle and human health risk assessments as tools for decision making in the design and implementation of nanofiltration in drinking water treatment plants. Sci. Total Environ. 2014, 466-467, 377-386.

34. Merkel, L.; Bicking, C.; Sekhar, D. Parents' perceptions of water safety and quality. J. Community Health 2012, 37, 195-201.

35. Castano-Vinyals, G.; Cantor, K.P.; Villanueva, C.M.; Tardon, A.; Garcia-Closas, R.; Serra, C.; Carrato, A.; Malats, N.; Rothman, N.; Silverman, D.; et al. Socioeconomic status and exposure to disinfection by-products in drinking water in Spain. Environ. Health 2011, 10, doi:10.1186/1476-069X-10-18.

36. Xu, B.B.; Xu, Q.J.; Liang, C.Z.; Li, L.; Jiang, L.J. Water quality assessment for heavy metals in rural groundwater sources around Shizhuyuan polymetallic mine in Chenzhou, Hunan Province. J. Environ. Eng. Technol. 2013, 3, 113-118.

37. Pfadenhauer, L.M.; Burns, J.; Rohwer, A.; Rehfuess, E.A. A protocol for a systematic review of the effectiveness of interventions to reduce exposure to lead through consumer products and drinking water. Syst. Rev. 2014, 3, doi:10.1186/2046-4053-3-36.

38. Huy, T.B.; Tuyet-Hanh, T.T.; Johnston, R.; Nguyen-Viet, H. Assessing health risk due to exposure to arsenic in drinking water in Hanam Province, Vietnam. Int. J. Environ. Res. Public Health 2014, $11,7575-7591$. 
39. Zobrist, J.; Sima, M.; Dogaru, D.; Senila, M.; Yang, H.; Popescu, C.; Roman, C.; Bela, A.; Frei, L.; Dold, B.; et al. Environmental and socioeconomic assessment of impacts by mining activitiesA case study in the Certej River catchment, Western Carpathians, Romania. Environ. Sci. Pollut. Res. 2009, 16, 14-26.

40. Few, R.; Lake, I.; Hunter, P.R.; Tran, P.G. Seasonality, disease and behavior: Using multiple methods to explore socio-environmental health risks in the Mekong Delta. Soc. Sci. Med. 2013, 80, 1-9.

(C) 2015 by the authors; licensee MDPI, Basel, Switzerland. This article is an open access article distributed under the terms and conditions of the Creative Commons Attribution license (http://creativecommons.org/licenses/by/4.0/). 